
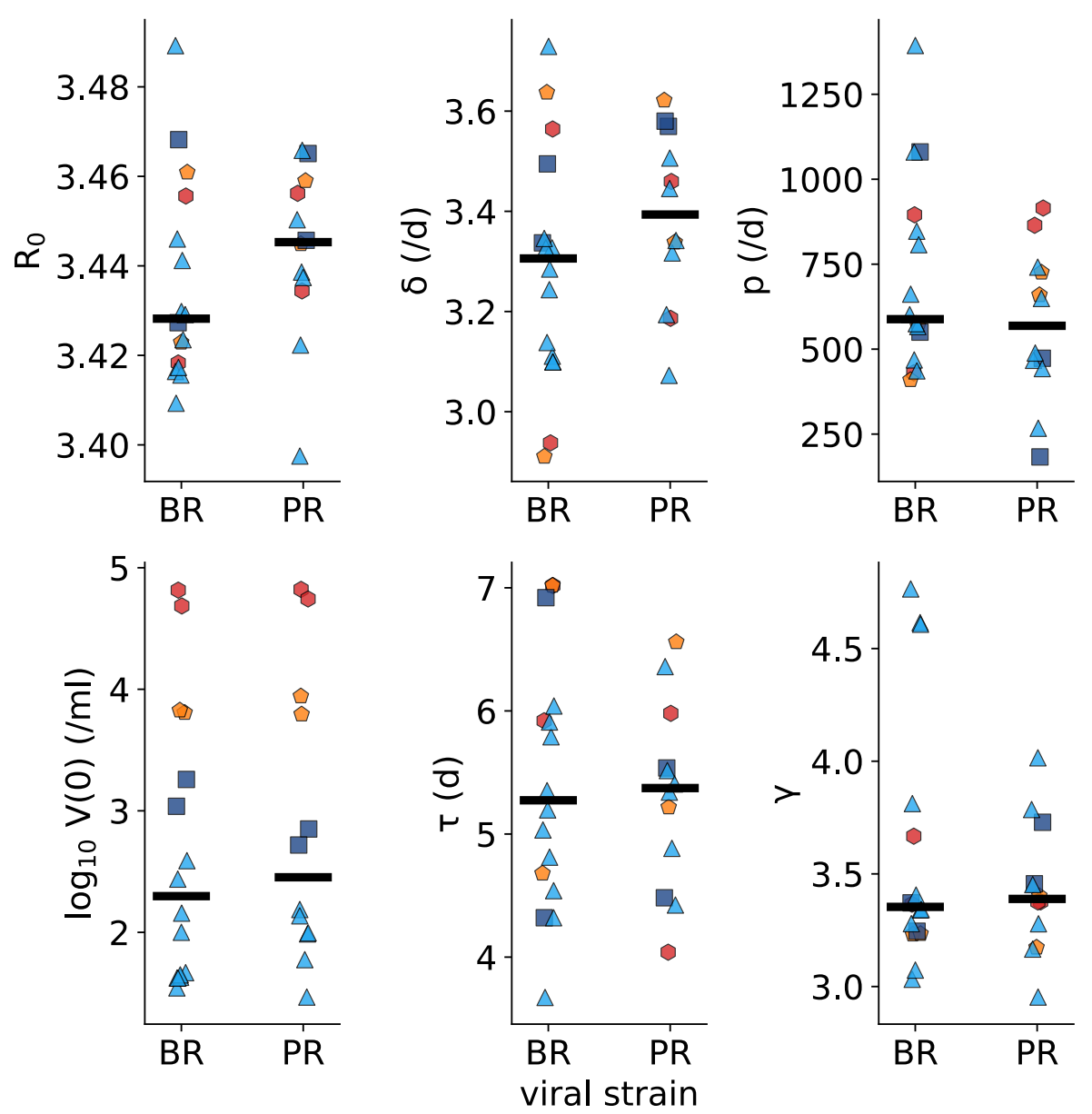

\title{
Supplementary Figure 14
}

Relationships between individual estimated parameters and viral strain, with individual estimated parameters from the innate immune model with reduced viral production rate (Eq. 2) with fixed $k$ $=8 \mathrm{~d}^{-1}$, fixed $c=10 \mathrm{~d}^{-1}$, fixed $s=1 \mathrm{~d}^{-1}$ and fixed $\alpha=2 \mathrm{~d}^{-1}$, and with a dose-dependency in $\log _{10} V_{0}$ explicitly incorporated (Supplementary Table 4). Differences between parameters by viral strain are assessed by the Mann Whitney $U$ test, and no significant relationships after Bonferroni correction are observed. Markers for individual animals are colored by the viral strain (BR: green triangles, PR: purple circles). 